\title{
Multiculturalism and inconsistency in the perception of sex education in Australian society
}

\author{
Ghanim Almahbobi
}

School of Biomedical Sciences, Curtin Health Innovation Research Institute, Curtin University, Kent St., Bentley, Perth, WA, 6102, Australia

Corresponding Author:

Dr. Ghanim Almahbobi

School of Biomedical Sciences, Curtin University, Bently, WA, Australia.

Email: g.almahbobi@curtin.edu.au

\section{Abstract}

A group of individuals who share common beliefs form a culture in which they communicate their values and attributes about certain aspects of society. Sex education remains one of the early teachings that humans experience irrespective of the race or level of development of a given society. However, different cultures perceive sex education differently due to differences in attitudes and beliefs, leading to significant diversity in the management of sex education among different societies across the globe. Many studies have found that in a traditional society with a homogeneous culture, the foremost reason for the different approaches to sex education is related to traditional values, in addition to other factors such as religion and political belief. In order to improve sex education, and consequently, sexual health in a modern multicultural society such as Australia, it becomes imperative to identify the inconsistency in beliefs about sex education among individuals with different cultural backgrounds in the Australian population. In this report, the author highlights similarities and differences in the methods employed by certain cultures of the Australian population. The report considers the different cultural environments of specific societies, the prevalence of sex education in these societies and how culture influences the prevalence. The concluding thoughts reflect on the success of the education programs in Australia, based on the idea that resolving the problems of sex education needs support from a number of bodies within Australian society.

Key Words

Sex education, multiculturalism, sexual health

\section{Introduction}

Although sexual activity or behaviour exists as a means rather than a goal for achieving human reproduction, in many people it significantly dominates the entire issue of human sexual proclivity whereby sexual pleasure constitutes the main interest rather than the focus being on actual reproduction. Sex education consists of elements such as knowledge and understanding the biological facts about reproductive cycles including growth and development, pregnancy and birth, and fecundity and infertility. Due to its beneficial aspects, sex education provides guidance about care, maintenance, safe sexual practices and improved health ${ }^{1}$ through such efforts as reduction in the incidences of sexually transmitted diseases or HIV and lowers the number of unwanted pregnancies and abortions. ${ }^{2}$

The inconsistency in sex education across the world calls for a global recognition of the underlying causes of such inconsistency to improve the standards of health outcomes in a population, specifically among young people. For example, the issue of varied sex education methodologies across the globe's various cultures should be considered in an attempt to achieve more consistency, especially since all humans reproduce in the same biological way. The research literature indicates that the foremost reason behind the variation in approaches derives from factors inherent in different cultures; hence culture possibly plays an active role in social reproduction, ${ }^{3}$ highlighting the importance of providing accurate sex education. In order to improve sexual health in populations such as inhabitants of Australia, homogeneous sex education and knowledge among young people becomes a desirable goal irrespective of the 
diverse backgrounds of individuals within the Australian population.

\section{Australian multiculturalism and diverse beliefs in sex education}

In a majority of societies particularly the underdeveloped and to a lesser extent developing countries, traditional values, religious beliefs and political authorities establish the foundation of their cultures. Currently, Australia represents a relatively young, modern and developed society, which exhibits a high degree of multiculturalism. Many backgrounds influence the emerging culture in Australia as a result of its native Indigenous culture and the incoming waves of migrating people into the country. Such diversity produces a strong attitude of inclusivity. The curricula of Australian states shows evidence of this inclusivity where teachers encourage all students to strive for a broad understanding of the contribution of their cultural heritages. However, this multicultural inclusivity comes with its own problems, primarily produced by the diversity of individual cultural norms, that include the aspects of intimacy, relationships and sex issues.

Since the establishment of an Australian nation, Australian society came predominantly under the influence of Christian Missionaries who founded many of the schools. The Christian Missionaries intend for the schools to be as modern as possible (in curriculum and resources) and support individual student development and at the same time conform to Christian morality. With this philosophy in mind, certain aspects of sex education would, for example, encourage students to use contraceptive methods instead of abstaining from sexual activities. Unfortunately, this way of thinking caused moral conflict, led to contradicting messages and restricted the effectiveness of sex education. ${ }^{4}$

Since Australian Indigenous people are influenced by their cultural beliefs and also disadvantaged by socio-economic conditions, some cultural beliefs exert negative effects on the mainstream Australian culture. Sex education in the Australian Indigenous culture differs substantially from the sex education received in the Western culture throughout Australia and Indigenous people receive substandard sex education. ${ }^{5}$ This fact becomes most obvious with the increased rate of rape and the rise in the incidence of sexually transmitted diseases within this fraction of the Australian population. The provision of sex education available to the Indigenous Australians purports to reduce the number of sexually transmitted infections, teenage pregnancies and sexual abuse that have occurred possibly from improper or a lack of sex education. Research shows a higher birth rate amongst teenage mothers in Aboriginal communities, four times the rate found in non-Indigenous teenage mothers. ${ }^{5}$

In strong traditional communities, the Indigenous culture clearly focuses on respecting the beliefs of tribal elders, who traditionally dictate appropriate behaviours, beliefs and practices. In addition to the Indigenous community, an influx of black Africans produces a growing source of Australian immigrants into Western Australia. Elders of black Africans in South Africa feel that modern concepts of sex education corrupt the moral status of young people, leading to loss of respect for cultural norms. ${ }^{6}$ Currently in South Africa, unmarried women are not allowed to speak openly about their active sexual status due to hostile feedback from elders. ${ }^{6}$

Some cultures possess a high degree of syncretism and support the coexistence of Christian religion along with premarital sex and pregnancy, but for Indians in the Australian population, sex remains a taboo activity. Traditional Indian culture views sex as a private act that should only occur between married couples, keeping young people 'uncorrupted' by health knowledge or sex education. ${ }^{6}$ In India, a country with the second highest number of people worldwide affected with HIV, incorporating Western values into sex education; that is a normal part of the mainstream Australian culture, may appear to corrupt Indian youth under traditional Indian culture.

In Western Australia for example, some Muslim immigrants may enter the country with traditional values about sexual issues. Many of these immigrants feel sex education promotes premarital sexual encounters and has no place in the schools' curricula. Since some Muslim immigrants might even believe that sending their children to schools dominated by Western values creates a detrimental environment which challenges their cultural values, specialised Islamic schools are on the rise.

With the discussion above on the rise in the diversity in cultural beliefs, Australia needs to consider implementing a more homogeneous and modern sex education program.

\section{Relevance of sex education to Australian adolescents} Youth receive sex education delivered through media, at schools and to a lesser extent at home. The media supplies by far the largest source of sex education material; though at the expense of providing a format of information particularly detrimental for younger people. Sex education in Australia targets secondary school 
students with an average age of 13.2 years, but for youths encountering sex at a younger age, this age is too late. ${ }^{7}$ In the 1970s major transformations occurred for addressing sex education, driven by the changing political and social culture of Australia. ${ }^{8}$ Sex education became "mandatory for all young people, male as well as female, and those under as well as those over 16 years of age". ${ }^{9}$ More recently the Australian Commonwealth Department of Health and Family Services developed a national set of guidelines for educating high school students on sex education. However, in many components of diverse Australian cultures, youth receive instruction to simply abstain from sexual activities, rather than, for example, learning about implementing protection methods to prevent HIV infection. However, culture and religion commonly control home-based sexeducation.

Nonetheless, sexually-active young people will continue sexual activity with or without the approval of society. Research indicates that teens aged 12-15 years believe that sexual and peer relationships reside as the most prominent issues in their lives, followed closely by familial associations. ${ }^{10}$ Studies in Australia support the views that most adolescents believe that it is 'normal' to have sex before the age of 17 years $^{11}$ and one-third of high school students encountered unwanted sex, underscoring the need for appropriate sex education. $^{12}$ The prevalence of teenage pregnancy probably increased due to the lack of information, support and love from the home situation, which, in turn, may significantly affect the number of teenage pregnancies in society. ${ }^{10}$

Consequently, appropriate education about sexuality and related health issues provide an avenue so students can make informed decisions before committing to a pleasure-onlydriven activity. The entire Australian society needs to support a comprehensive program of sex education for a successful program. If policy makers addressed prevention and transmission of HIV and other outstanding sexually transmitted conditions, students might be able to bridge the gap between knowledge and their surrounding cultural environment. A comprehensive program could provide benefits for the country in regards to a positive impact on HIV rates, unwanted pregnancy and abortion rates that otherwise will continue to rise and negatively affect the national economy.

\section{Conclusion}

Diversity in the background cultures of Australia will influence the success and direction of sex education programs. The sex education program focus could raise a concern specifically for women ${ }^{13}$ and adolescents ${ }^{14}$ who really could benefit from an appropriate sex education program. The current viewpoint based on traditional cultures emphasises that sex education corrupts youth. A policy refocus could change the sex education program to something that benefits adolescents' development and the well-being of the country. Some believers of traditional cultures view sex education as a platform to encourage sexual activity among teenagers. In contrast, research demonstrates that ignorance of sex education increases the chance of unwanted pregnancies and the prevalence of teenage parenthood. ${ }^{11}$ Society should supply youth with accurate, reliable sources of information relating to sexual issues rather than forcing young adults to sources of unreliable, less-than-accurate information, such as internet-based pornographic literature, tough guys or experienced relatives. ${ }^{15}$ Sex education reform requires support and collaborative effort. A comprehensive program is needed, supported by the whole community including parental commitment and seriously committed media campaigns. ${ }^{11}$ Research indicates effective sex education requires parental involvement. ${ }^{15}$ Schools remain major networks of human development. With the right support from government, non-government organisations, religious groups and local communities, schools can achieve successful programs. Planning sex education programs involves multidisciplinary skills and pragmatic partnerships. ${ }^{3}$ Basic elements of successful education programs in a modern Australian society require knowledge of Australian diverse cultures and related beliefs about sex education.

\section{References}

1. Wright S, Ryan M, Gabb R. Reproductive health: the knowledge, attitudes and needs of adolescents. The Royal Australian College of Obstetricians and Gynaecologists, Melbourne, Australia. 1989.

2. Kippax S, Stephenson N. A meaningful evaluation of sex and relationship education. Sex Education. 2005;5(4):359373.

3. Hemingway J. Reframing sex education. Sex Education. 2006;6(4):313-315.

4. Pfeiffer J. Condom social marketing, Pentecostalism, and structural adjustment in Mozambique: a clash of AIDA prevention messages. Med Anthropol Q. 2004 Mar;18(1):77-103.

5. Larkins SL, Page RP, Panaretto KSP, Scott R, Mitchell MR et al. Attitudes and behaviours of young Indigenous people in Townsville concerning relationships, sex and contraception: the "U Mob Yarn Up" project. Med J Aust. 2007 May 21;186(10):513-8.

6. Lambert H, Wood K. A comparative analysis of communication about sex, health and sexual health in 
India and South Africa: Implication of HIV prevention. Culture Health and Sexuality. 2005;7:527-541.

7. Global Sex Survey Results. [homepage on the Internet]. 2005. Available from:

http://sex.data360.org/dataset.aspx?data_set_ID=4566

8. Weaver S, Smith G, Kippax S. School-based sex education policies and indicators of sexual health among young people: a comparison of the Netherlands, France, Australia and the United States. Sex Education. 2005;5:171-188.

9. Mindel A, Kippax S. A national sexually transmissible infections strategy: the need for all embracing approach. Med J Aust. 2005 Nov 21;183(10):502-3.

10. McDevitt TM, Ormrod JE. Child development. $6^{\text {th }}$ edition. New Jersey: Pearson Education International; 2004.

11. Williams S, Davidson S. Improving adolescent sexual and reproductive health. A view from Australia: learning from world's best practice. Sex Health. 2004;1(2):95-105.

12. Farouque F. Teenagers want sex - but a third get unwanted sex. The Age. [Internet]. 2009 August 4,. Available from: http://sex.theage.com.au/lifestyle/lifematters

13. Gordon G, Mwale V. Preventing HIV with young people: a case study from Zambia. Reprod Health Matters. 2006 Nov;14(28):68-79.

14. Gilbert J. Risking a relation: sex education and adolescent development. Sex Education. 2007;7:47-62.

15. Capoor I, Mehta S. Talking about love and sex in adolescent health fairs in India. Reproductive Health Matters.

1995;3:22-7.

\section{ACKNOWLEDGEMENTS}

N/A

\section{PEER REVIEW}

Not commissioned. Externally peer reviewed.

\section{CONFLICTS OF INTEREST}

The author declares that there is no competing interest.

\section{FUNDING}

N/A

\section{ETHICS COMMITTEE APPROVAL}

N/A 